\title{
A 65-Year-Old Female with Paget's Disease of Skull
}

\author{
Syed Arshad Mustafa ${ }^{1}$ \\ Received: November 27, 2015 Accepted: April 25, 2016 \\ doi: http://dx.doi.org/10.3329/jemc.v6i2.27767
}

\begin{abstract}
Paget's disease (PD) of the bone is a chronic metabolic disorder involving increased bone turnover with abnormal repair, leading to bony deformities and associated pain. It is characterised by a disturbance in bone modelling and remodelling because of increased osteoclastic activity followed by improper osteoblastic repair. Although PD of bone is an uncommon entity, axial skeleton involving pelvic bones, spine and skull are the commonest sites. Here we report a case of 65-yearold postmenopausal female who presented with generalised bone pain and subsequently was diagnosed as a case of Paget's disease and managed accordingly.
\end{abstract}

Keywords: Paget's disease; Cotton-wool spots; Alkaline phosphatase; Bisphosphonates

J Enam Med Col 2016; 6(2): 106-109

\section{Introduction}

Paget's Disease (PD) of bone is relatively an uncommon entity in Asian nations especially India. $1,2,3$ It is more prevalent in European nations and people of Anglo Saxon origin. ${ }^{4}$ The overall prevalence of PD is 3 to $3.5 \%$ and this increases with age. ${ }^{5}$ It is mostly seen in the middle aged and elderly, though 'juvenile pagets' is a known entity, where patients are usually less than forty years of age and have an aggressive clinical course. $^{6}$ Males are affected more than than females. ${ }^{7}$ Many a times patients are asymptomatic ${ }^{8}$ and the disease is incidentally picked up by radiologists or at a tertiary care centre, when patients are being evaluated for other diseases. ${ }^{7}$ Clinical course of the disease is insidious and over a period of time patients develop symptoms of bone pain, facial deformity, fractures and other complications like hearing impairment and compressive myelopathy. PD of bone occurs in two forms, monostotic (involving one bony site) and polyostotic (involving many sites). Compared to other bony sites, PD of skull has been shown to be associated with a poorer prognosis. ${ }^{9}$ Treatment is individualised, with emphasis on symptom control and minimizing complications and involves pharmacotherapy with antiresorptive drugs like bisphosphonates and calcitonin. Remission induction is assessed by symptomatic improvement and normalisation of markers like alkaline phosphatase. ${ }^{9}$

\section{Case report}

A 65-year-old postmenopausal female presented to medical outpatient department with complaints of generalised bone pain for last six months. The pain was dull aching, continuous, predominantly nocturnal particularly involving the long bones, ribs and skull. She had been diabetic for last ten years, hypertensive and hypothyroid for last five years. She was taking insulin, tablet amlodipine and thyroxine. There was no history of fever, arthritis, weight loss, anorexia, vomiting, constipation, weakness of any part of body, headache, tinnitus, giddiness, visual disturbance, recurrent chest or urine infection or intake of any prolonged vitamin supplements or supplemental injections. There was no history of such ailment in the family. Physical examination revealed normal vitals, no pallor, cyanosis, jaundice, lymphadenopathy or organomegaly. Tenderness could be elicited only on skull bones and nowhere along the painful areas. ENT and central nervous system examinations were normal. Patient was investigated for following parameters. 


\begin{tabular}{|c|c|c|c|}
\hline Serial & Parameters & Values & Reference values \\
\hline 1 & Hemoglobin & $13 \mathrm{gm} / \mathrm{dL}$ & $12-15 \mathrm{gm} / \mathrm{dL}$ \\
\hline 2 & Random bloodglucose & $98 \mathrm{mg} / \mathrm{dL}$ & $80-100 \mathrm{mg} / \mathrm{dL}$ \\
\hline 3 & Urea & $32 \mathrm{mg} / \mathrm{dL}$ & $0-40 \mathrm{mg} / \mathrm{dL}$ \\
\hline 4 & Creatinine & $1.9 \mathrm{mg} / \mathrm{dL}$ & $0.5-1.5 \mathrm{mg} / \mathrm{dL}$ \\
\hline 5 & $\mathrm{pH}$ & 7.35 & $7.35-7.45$ \\
\hline 6 & $\mathrm{HCO} 3$ & $22 \mathrm{mEq} / \mathrm{L}$ & $18-30 \mathrm{mEq} / \mathrm{L}$ \\
\hline 7 & $\mathrm{pCO} 2$ & $37 \mathrm{~mm} \mathrm{Hg}$ & $35-45 \mathrm{~mm} \mathrm{Hg}$ \\
\hline 8 & Urine routine examination & Normal & \\
\hline 9 & S. bilirubin & $1.2 \mathrm{mg} / \mathrm{dL}$ & $0.2-1.5 \mathrm{mg} / \mathrm{dL}$ \\
\hline 10 & AST & $53 \mathrm{U} / \mathrm{L}$ & $0-40 \mathrm{U} / \mathrm{L}$ \\
\hline 11 & ALT & $30 \mathrm{U} / \mathrm{L}$ & $0-30 \mathrm{U} / \mathrm{L}$ \\
\hline 12 & Total protein & $7.7 \mathrm{gm} / \mathrm{dL}$ & $6-8 \mathrm{gm} / \mathrm{dL}$ \\
\hline 13 & Albumin & $4.8 \mathrm{gm} / \mathrm{dL}$ & $3.5-5.5 \mathrm{gm} / \mathrm{dL}$ \\
\hline 14 & Alkaline phosphatase & $1490 \mathrm{U} / \mathrm{L}$ & $0-160 \mathrm{U} / \mathrm{L}$ \\
\hline 15 & Gamma glutamase & $14.2 \mathrm{U} / \mathrm{L}$ & $0-30 \mathrm{U} / \mathrm{L}$ \\
\hline 16 & Electrocardiogram & Normal & \\
\hline 17 & Ultrasonography of abdomen & Normal & \\
\hline 18 & Chest radiograph & Normal & \\
\hline 19 & Skull radiograph (Fig 1) & $\begin{array}{l}\text { Diffuse calvarial thickening with } \\
\text { multiple areas of focal sclerosis } \\
\text { (cotton wool appearance) }\end{array}$ & \\
\hline 20 & Serum calcium & $9.8 \mathrm{mg} / \mathrm{dL}$ & $8.5-10.5 \mathrm{mg} / \mathrm{dL}$ \\
\hline 21 & Serum phosphorus & $3.9 \mathrm{mg} / \mathrm{dL}$ & $4-7 \mathrm{mg} / \mathrm{dL}$ \\
\hline 22 & Parathyroid hormone & $44 \mathrm{pg} / \mathrm{mL}$ & $10-71 \mathrm{pg} / \mathrm{mL}$ \\
\hline 23 & Magnesium & $2.1 \mathrm{mg} / \mathrm{dL}$ & $1.8-3.6 \mathrm{mg} / \mathrm{dL}$ \\
\hline 24 & 25-OH Vit. D & $16.8 \mathrm{pg} / \mathrm{mL}$ & $19-58 \mathrm{pg} / \mathrm{mL}$ \\
\hline 25 & TSH & $19.08 \mathrm{mIU} / \mathrm{L}$ & $0.5-5.0 \mathrm{mIU} / \mathrm{L}$ \\
\hline 26 & ANA & Negative & \\
\hline 27 & Urine for Bence Jones proteins & Negative & \\
\hline 28 & Serum and Urine electrophoresis & Negative for M-band & \\
\hline 29 & High resolution neck sonography & $\begin{array}{l}\text { Normal scan, no parathyroid } \\
\text { adenoma }\end{array}$ & \\
\hline 30 & MDP whole body scan & Increased tracer uptake at skull & \\
\hline 31 & MIBI Tc ${ }^{99 m}$ parathyroid scan & No abnormal tracer uptake & \\
\hline 32 & Axial CT scan skull including base of skull (Fig2) & $\begin{array}{l}\text { Pronounced thickening of inner } \\
\text { table with widening of diploic } \\
\text { spaces. Multiple sclerotic areas in } \\
\text { diploic spaces. }\end{array}$ & \\
\hline 33 & ENT examination & Normal & \\
\hline 34 & DEXA Scan & $\begin{array}{l}\text { T score, } 2 \\
\text { BMD }=0.63 \mathrm{gm} / \mathrm{cm}^{2}\end{array}$ & \\
\hline
\end{tabular}


Radiological evidence along with raised alkaline phosphatase in the clinical setting pointed towards diagnosis of Paget's disease. Concomitantly other differentials were ruled out.

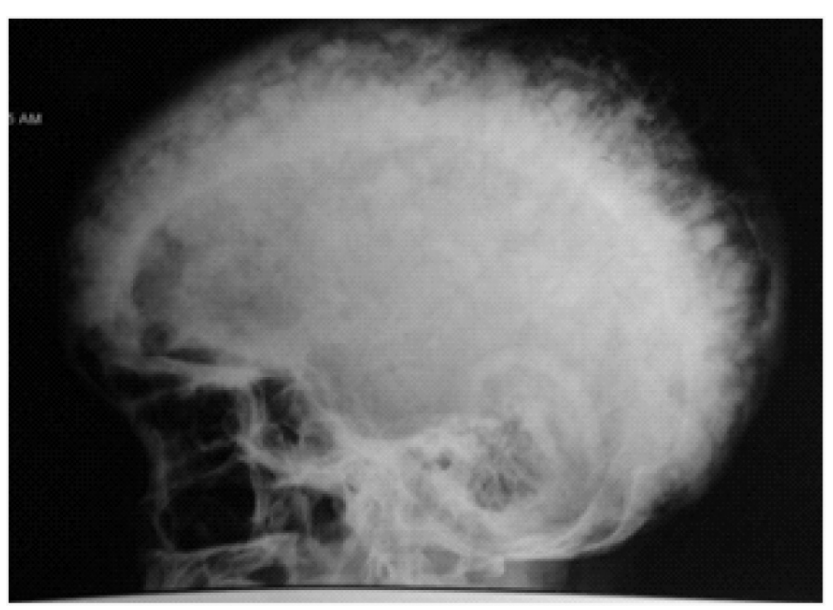

Fig 1. X-ray skull showing 'cotton wool spot' sign

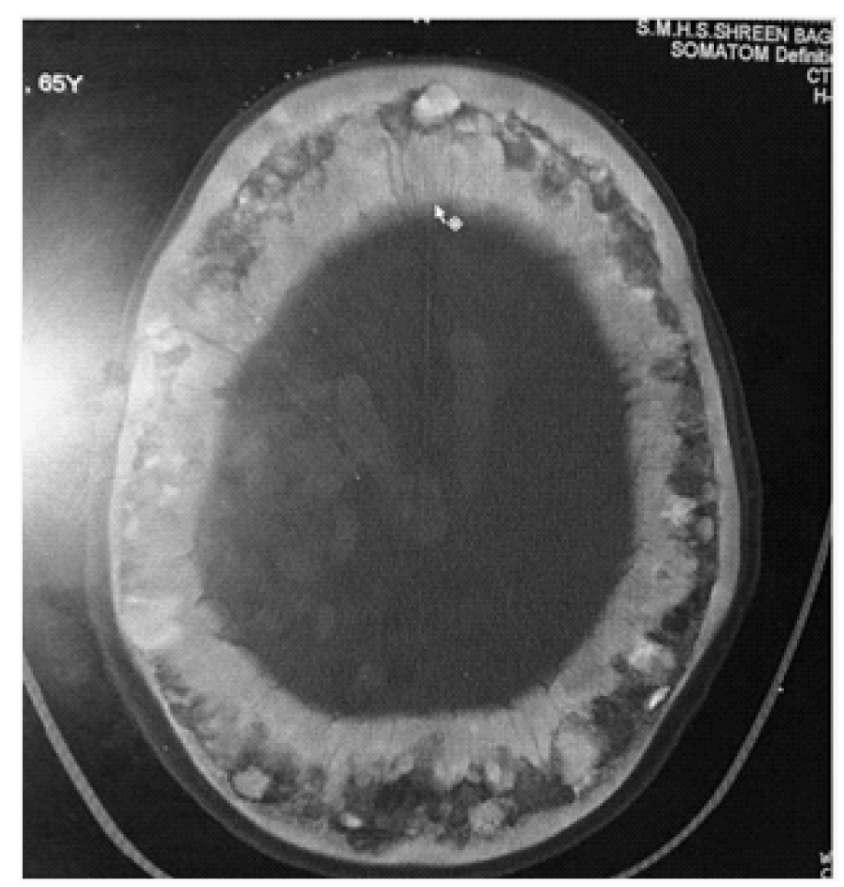

Fig 2. CT skull showing thickened calvarium with increase in diploic spaces

\section{Discussion}

Paget's disease of bone is a rare phenomenon in India with only a few cases being reported so far. ${ }^{2,7}$ Reason for its rarity remains unknown. ${ }^{3}$ The cause of Paget's disease is unknown, but a strong genetic influence has been suspected. ${ }^{7}$ Mutations in the 'sequestosome 1/p62' gene has been proposed as a possible cause of familial Paget's disease and of some apparently sporadic cases of the disease. The epidemiological characteristics of the disease suggest possible environmental influences in its aetiology. ${ }^{7} \mathrm{PD}$ has an insidious asymptomatic course and needs a high clinical suspicion for diagnosis. It is essentially diagnosed radiologically while evaluating raised alkaline phosphatase levels unexplained by other causes. ${ }^{7}$ The clinical course of PD follows three phases, osteolytic, intermediate and sclerotic phase. ${ }^{10}$ Early in the course of disease, lytic phase predominates causing focal osteolytic lesions. Technetium scintigraphy in this phase shows marked increases of radio tracer accumulation, as evident in our case. Sclerotic phase follows the intermediate phase and has characteristic radiological features like mixed lytic and sclerotic areas, thickened trabeculae, bone expansion, cortical thickening and deformity. ${ }^{8}$ At times sclerotic phase presents a radiological dilemma, as bone expansion conventionaly seen with PDB is not seen in a few cases, especially when PDB arises at areas known to be conventional sites for bony metastasis in breast and prostate cancer (pelvis and lower vertebra). ${ }^{10} \mathrm{~A}$ radioisotope scan is usually recommended as part of diagnostic evaluation to look for sites of potential complications like base of skull (BOS), vertebra and long bones (in our case BOS disease). PD of skull has been seen to show various radiographical features depending upon the phase and extent of the disease like 'osteoporosis circumscripta', 'Tam O' Shanter' and as in our case 'cotton wool spot' sign. ${ }^{8}$ PD of skull is usually associated with BOS involvement with subsequent neuro-otological complications like sensorineural deafness, hydrocephaly and cranial neuropathies. ${ }^{9,11}$ CT-myelography or magnetic resonance imaging (MRI) scanning are crucial to determine compression of neural structures and to exclude other causes. These investigations were not done in our case in view of no clinical features suggestive of neuronal compromise as audiogram in this patient was normal. CT scan only showed thickened calvarium with increase in diploic spaces.

Alkaline phosphatise (ALP) is the most useful bone marker in the diagnosis and evaluation of response in PDB. The levels of ALP corroborate with the extent of disease, with studies showing its role in subsequent follow-up also. ${ }^{9}$ Our patient had ALP level of 1490 (nine times normal value), with normal calcium and 
PTH levels. Serum levels of $25-\mathrm{OH}$ vitamin were slightly on the lower side, which might be a coincidental finding in a osteoporotic postmenopausal female explaining the generalised bony pains associated with low bone marrow density (BMD) and osteopenic dual energy x-ray absorptometric (DEXA) findings. Myeloma work up was negative with normal creatinine, calcium levels and no M-band seen on serum electrophoresis. Occasional association of PD with hyperparathyroidism (HPT) has been reported ${ }^{7}$, but in our case HPT and parathyroid adenoma were ruled out with normal levels of serum calcium and a normal $\mathrm{Tc}^{99}$ MIBI scan respectively.

Treatment of PD is essentially aimed at alleviation of symptoms (immediate objective) and minimising disease progression and skeleton-related event (long term motive). Antiresorptive treatment with bisphosphonates are the benchmark of treatment in PD. ${ }^{12}$ Historically, parenteral calcitonin has been used but the short half-life, frequent relapses after stoppage of therapy and resistance to treatment have limited its use. ${ }^{13}$ The goal of the therapy is to induce full remission, depicted by symptom improvement and normal levels of markers of bone turnover (alkaline phosphatase). Bisphosphonates reduce pain and improve the osteogenic remodelling. Earlier oral formulations like pamidronate and alendronate were used, but now-a-days injectable bisphosphonates are available. Most of the studies suggest continued treatment till normalisation of markers, which is seen to be around six months ${ }^{7}$, after which treatment is discontinued and patient is followed up with three monthly bone markers ${ }^{14}$; treatment is restarted if there is $25 \%$ increase in markers over the baseline value. ${ }^{14}$ Post-treatment osteolytic lesions on skull appear sclerotic whereas bone scan analyses show marked improvement in up to eighty percent of the patients; in up to $20 \%$ of cases there is still residual uptake despite adequate control of the disease. ${ }^{13}$

Our case was a monostotic Paget's disease of skull without any neurological or otological complications. Diagnosis was made by typical radiological picture and high serum alkaline phosphatase levels; so aggressive interventional diagnostic modalities like bone biopsy were omitted. The response to bisphosphonates therapy was excellent with clinical improvement and normalisation of alkaline phosphatase values carried out at the end of three months. Patient required reevaluation for radiological and radionuclide response, but was lost to follow-up.

\section{References}

1. Hadjipavlou AG, Gaitanis IN, Kontakis GM. Paget's disease of the bone and its management. J Bone Joint Surg (Br) 2002; 84B:160-169.

2. Chakrabarty RP, Bhardwaj OP. Paget's disease of the bone. J Indian Med Assoc 1963; 41: 126-127.

3. Sridhar GR. Paget's disease in India. Is it truly rare? Natl Med J India 1994; 7: 101.

4. Atti CD, Cassar-Pullicino VN, Lalam RK, Tins BJ, Tyrrell PNM. The spine in Paget's disease. Skeletal Radiol 2007; 36(7): 609-626.

5. Collins DH. Paget's disease of bone; incidence and subclinical forms. Lancet 1956; 271 6933: 51-57.

6. Holdago S, Rotes D, Guma M, Monfort J, Olive A, Carbonell $\mathrm{J}$ et al. Paget's disease of bone in early adult life. Ann Rheum Dis 2005; 64(2): 306-308.

7. Joshi SR , Ambhore S, Butala N, Patwardhan M, Kulkarni M, Pai B et al. Paget's disease from Western India. JAPI 2006; 54: $535-538$.

8. Shankar YU, Misra SR, Vineet DA, Baskaran P. Contemporary Clinical Dentistry 2003; 4(2): 227-230.

9. Catalina P, Carsote M, Hortopan D, Coculescu M. Skull monostotic pagets disease of bone- case report \& review of literature. Acta Endocrinologica (Buc) 2007; 3(3): 333-344.

10. Sundaram M. Imaging of Paget's disease and fibrous dysplasia of bone. Journal of bone \& mineral research 2006; 21(2): 28-30.

11. Teufert KB, Linthicum F Jr. Paget disease and sensorineural hearing loss associated with spiral ligament degeneration. Otol Neurotol2005; 26(3): 387-391.

12. Papapoulos SE. Paget's disease of bone: clinical, pathogenetic and therapeutic aspects. Bailliere's Clinical endocrinology and metabolism 1997; 11: 117-143.

13. Bhatt K, Balakrishnan C, Mangat G, Bajan K, Ashavaid T, Joshi VR. Paget's disease of the bone: a report of three cases. JAPI 2006; 54: 571-574.

14. Alvarez L, Ricos C, Peris P, GuaNabens N, Monegal A, Pons $\mathrm{F}$ et al. Components of biological variation of biochemical markers of bone turnover in Paget's bone disease. Bone 2000; 26: 571-576. 